\title{
Rheological Investigation with Palierne's Model on a Polystyrene/Nylon 6 Blending Melt Compatibilized by a Polystyrene Grafted Maleic Anhydride
}

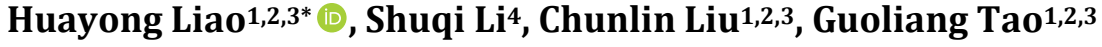 \\ ${ }^{1}$ Jiangsu Key Laboratory of Environmentally Friendly Polymeric Materials, School of Materials Science and Engineering, Jiangsu, \\ China \\ ${ }^{2}$ Jiangsu Collaborative Innovation Center of Photovolatic Science and Engineering, Changzhou University, Changzhou, China \\ ${ }^{3}$ National Experimental Demonstration Center for Materials Science and Engineering, Changzhou University, Changzhou, \\ China \\ ${ }^{4}$ Department of Mechanical and Electronic Engineering, Changzhou Vocational Institute of Engineering, Changzhou, China \\ Email: *roynetlhy@163.com
}

How to cite this paper: Liao, H.Y., Li, S.Q., Liu, C.L. and Tao, G.L. (2020) Rheological Investigation with Palierne's Model on a Polystyrene/Nylon 6 Blending Melt Compatibilized by a Polystyrene Grafted Maleic Anhydride. Open Journal of Organic Polymer Materials, 10, 17-25.

https://doi.org/10.4236/ojopm.2020.102002

Received: December 30, 2019

Accepted: February 22, 2020

Published: February 25, 2020

Copyright $\odot 2020$ by author(s) and Scientific Research Publishing Inc. This work is licensed under the Creative Commons Attribution International License (CC BY 4.0).

http://creativecommons.org/licenses/by/4.0/

\begin{abstract}
The dynamic rheological behaviors are measured by small amplitude oscillatory shear on a rotational rheometer for a polystyrene (PS)/nylon 6 (PA6) blend compatibilized by a polystyrene grafted maleic anhydride (PS-g-MAH). The storage moduli versus angular frequency $(G-\omega)$ data of the blends are fitted by Palierne model. The Palierne model fits the data basically well for the PA6-rich blends and the 70/6/30 (PS/PS-g-MAH/PA6) blend. The fitting results show that the PS-g-MAH has a fine compatibilizing effect on the PS/PA6 blends.
\end{abstract}

\section{Keywords}

Rheology, Palierne's Model, PS/PA6 Blend, Interfacial Tension

\section{Introduction}

In order to obtain new and fine polymer materials, many methods such as filling and blending have been developed for many years. Generally polymer blends have advantages than single components. But most polymer blends are immiscible, which affects the final properties, thus it is necessary to increase the miscibility of the blends. The miscibility of polymer blend has been studied by various methods including rheological method [1] [2]. The miscibility of polymer blend 
is affected by many factors such as molecular weight and molecular weight distribution, composition ratio, temperature, etc. Dynamic rheological behavior of polymer is sensitive to the structure and morphology [3]. Depending on composition, shear history, temperature, etc., polymer blends may present different morphologies such as droplet/matrix, co-continuous morphology and phase inversion.

Besides experimental work, some theoretical models cannot be neglected in investigating the linear viscoelasticity of polymer blends. Palierne's model [4] is one of the classic emulsion models and has been proved to be appropriate to predict the linear viscoelasticity of polymer blends. The interfacial tension between the blend components can be inferred by Palierne's model when the linear dynamic data are known. It should be emphasized that Pailierne's model can only describe polymer blend with droplet/matrix morphology. Origional $\mathrm{Pa}$ lierne's model [4] [5] considers interfacial tension as well as surface dilatation modulus and surface shear modulus. If surface dilatation modulus and surface shear modulus can be neglected, then simplified Palierne's model appears. Similar emulsion model such as Bousmina's model [6] can also predict linear viscoelasticity of polymer blends with only one parameter, i.e. interfacial tension. The interaction between droplets has not been considered in Palierne's model. Lee and Park model [7] considers the steric interaction or anisotropic effects [8]. Gramespacher and Meissner model [9] highlights the interface besides two phases of polymer blends. For blend with co-continuous morphology, it is difficult to develop a model to predict the dynamic modulus. Palierne's model as well as Bousmina's model can only work for blends with droplet/matrix morphology. In this case, a model was proposed by Yu and co-workers [10] based on a mechanical model. More work needs to be done to discover the relationship between rheological behavior and co-continuous morphology of blend.

Recently a PS/PA6 blend compatibilized by various components has been frequently investigated [11] [12] [13] [14]. The toughness and failure mode of PA6/mSEBS/PS ternary blends were studied with an oil-extended viscoelastic controlled interface [11]. Here mSEBS means maleic-anhydride-modified styrene-ethylene-butylene-styrene copolymer. Their results showed controlling of the physical properties of the PS/PA6 interface played an important role in improving the function of the material. It was reported [12] that increase of hydrophilic silica nanoparticles $\left(\mathrm{SiO}_{2}\right)$ affected greatly the relaxation and breakup dynamics of selectively filled polyamide (PA6) droplets with different degrees of deformation in polystyrene (PS) matrix during quiescent annealing. The authors considered that the enhancement of shape stability of PA6 droplets was mainly due to the viscoelastic properties of PA6 droplets after the addition of nanoparticles, rather than the reduction in interfacial tension. A similar blending material has been prepared by Wang and co-workers [13], with amino-modified nanosilica particles $\left(\mathrm{mSiO}_{2}\right)$ selectively localized at the interface of the $\mathrm{PS} / \mathrm{PA} 6 / \mathrm{mSiO}_{2}$ composites with co-continuous morphology via reactive extrusion. They found the MAH content of Styrene maleic anhydride (SMA) macromolecules has a large effect on the distribution of nanosilica particles. In one 
earlier research [14], reactive compatibilization using a miscible compatibilizer (SMA2) excellently controlled phase morphologies of the PS/PA6 and (PPE/PS)/PA6 blend. In the research [12] rheological investigation appears to be useful in discovering a role of interface of the PS/PA6 blend. We consider not only experimental research but also model fitting helps discover the relationship between phase structure and properties. In this work, the rheological behavior of a PS/PA6 blend compatibilized by polystyrene grafted maleic anhydride (PS-g-MAH) is investigated. Furthermore, Palierne's model is applied to analyze the interface miscibility of the blends and the results are meaningful.

\section{Experimental}

\subsection{Materials}

PS PG-33, produced by Zhenjiang Qimei Chemical Co. Ltd, China. Its melt flow rate (MFR) is $9.14 \mathrm{~g} / 10 \mathrm{~min}$, measured at $210^{\circ} \mathrm{C}, 2.16 \mathrm{~kg}$. PA6 1013B, Japan Ube, $\mathrm{MFR}=45 \mathrm{~g} \cdot(10 \mathrm{~min})^{-1}$, measured at $250^{\circ} \mathrm{C}, 2.16 \mathrm{~kg}$. A polystyrene grafted maleic anhydride (PS-g-MAH), is homemade with a grafting rate of $1.0 \%$.

\subsection{Preparation of Blends}

The materials were dried at $85^{\circ} \mathrm{C}$ for $12 \mathrm{~h}$ in an electric blast drying oven, then were mixed in a high-speed mixer (produced by Fuxin Light Industry Machinery Factory, Liaoning, China) with the weight ratio PS/PP-g-MAH/PA6 of 100/6/0, $90 / 6 / 10,70 / 6 / 30,50 / 6 / 50,30 / 6 / 70,10 / 6 / 90$ and 0/6/100). After that the samples were fed into a co-rotating twin screw extruder (type SHJ-35, made in Rubber and plastic machinery factory in Guangzhou, China), melt and extruded through a die, then were cooled under water, granulated by a granulator, and were dried at $120^{\circ} \mathrm{C}$ for $12 \mathrm{~h}$ in an electric blast drying oven. The rotating speed of the screw extruder was $110 \mathrm{r} / \mathrm{min}$, the feeding speed was $100 \mathrm{r} / \mathrm{min}$, and the temperature of the nine zones of the barrel was $150^{\circ} \mathrm{C}, 170^{\circ} \mathrm{C}, 190^{\circ} \mathrm{C}, 210^{\circ} \mathrm{C}, 230^{\circ} \mathrm{C}, 230^{\circ} \mathrm{C}$, $230^{\circ} \mathrm{C}, 230^{\circ} \mathrm{C}$ and $230^{\circ} \mathrm{C}$, the temperature of the die was $235^{\circ} \mathrm{C}$.

\subsection{Measurement}

Scanning electron microscope (SEM): the sample was thrust at an Izod impact test machine ADN-5.5 produced by Hengshang industrial equipment Co., LTD, Suzhou, China. The cross section was sprayed with gold and was observed by SEM LE0438VP made by Hitachi company, Japan. The average dispersed phase size is calculated by a software Nano Measurer 1.2.0.

Rheological measurement: small amplitude oscillatory shear was applied by using a rotational rheometer MCR301 made by Anton Paar GmbH of Germany with two parallel plates. The diameter of the plate is $25 \mathrm{~mm}$, the gap of the two plates was $1 \mathrm{~mm}$. The temperature in the experiment was $230^{\circ} \mathrm{C}$, and the angular frequency was from $0.1 \mathrm{rad} / \mathrm{s}$ to $300 \mathrm{rad} / \mathrm{s}$ in ascending order. The measurement was under nitrogen gas to avoid the oxidization of the samples. Before the start of the measurement the samples were kept for 5 min between the gap of the two 
plates to eliminate thermal history. The linear viscoelastic regime was determined by applying strain sweeping.

\section{Results and Discussion}

\subsection{Dynamic Rheological Curves of PS/PS-g-MAH/PA6 Blends}

Figure 1 shows the morphology of the PS/PS-g-MAH/PA6 blends with two weight ratios $70 / 6 / 30$ and $30 / 6 / 70$, respectively. Figure 1 (a) shows the morphology of 70/6/30 blend. It is a droplet/matrix structure with average droplet diameter $1.9 \mu \mathrm{m}$, obviously PA6 phase is the droplet and PS is the matrix. The $30 / 6 / 70$ blend shows a droplet/matrix morphology as shown in Figure 1(b), the dispersed phase is PS and the matrix is PA6 phase. The average droplet diameter is $2.6 \mu \mathrm{m}$, which is higher than the 70/6/30 blend, because PA6 phase has a lower viscosity than PS phase, thus PA6 can be deformed easier than PS phase. Balance between coalescence and breakup controls the morphology of the blend.

Figure 2 shows the dynamic rheological curves of the blends. Figure 2(a)

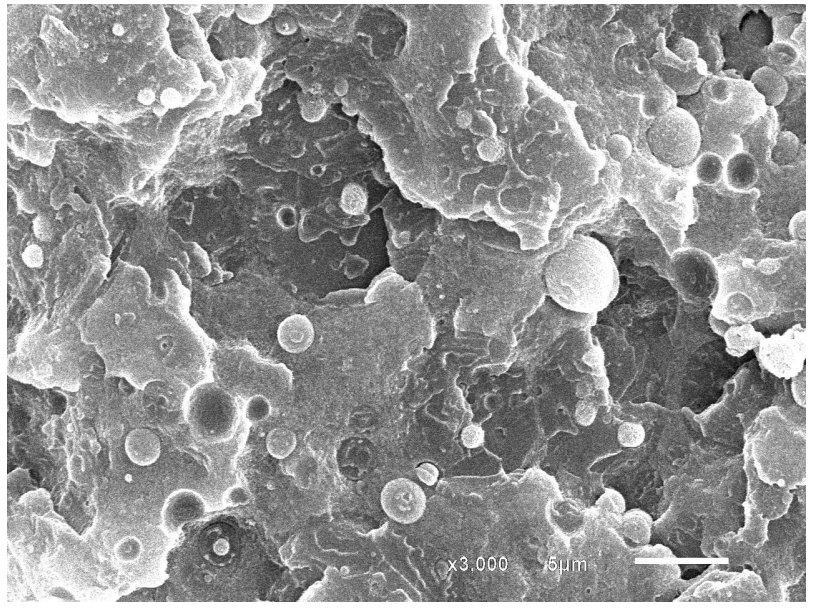

(a)

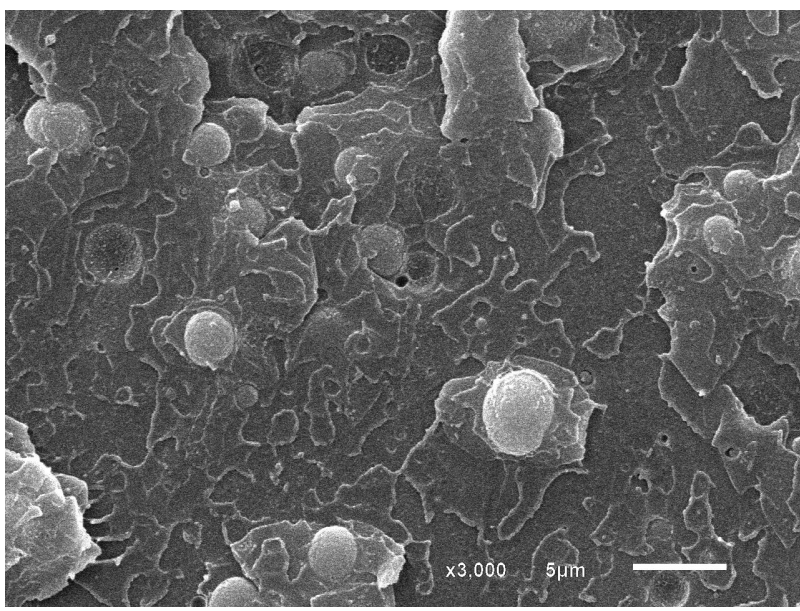

(b)

Figure 1. SEM images of the PS/PS-g-MAH/PA6 blends. (a) SEM image of the 70/6/30 blend; (b) SEM image of the 30/6/70 blend. 

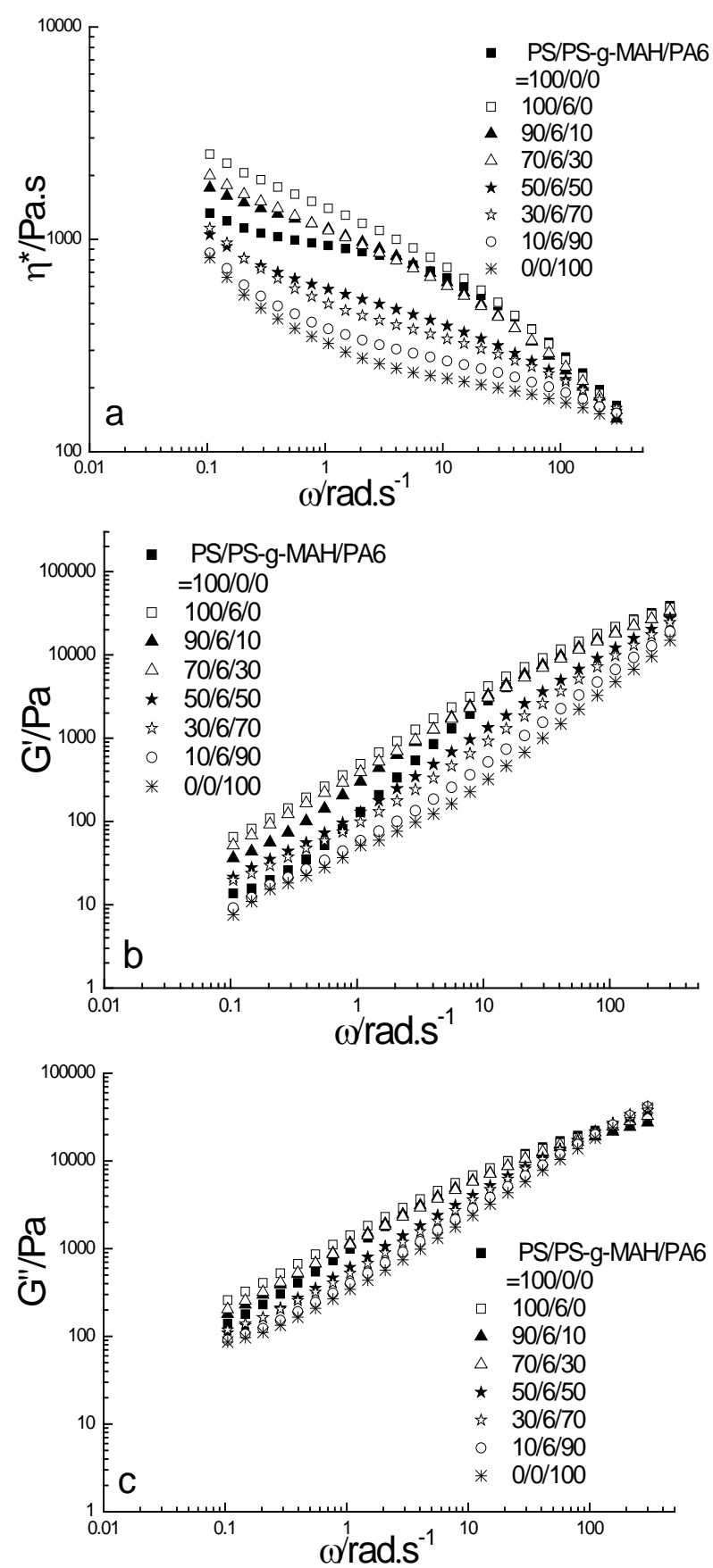

Figure 2. (a) Complex viscosity, (b) Storage modulus and (c) loss modulus vs angular frequency of PS/PS-g-MAH/PA6 blends at $230^{\circ} \mathrm{C}$.

shows the complex viscosity versus angular frequency of the blends. The 100/6 (PS/PS-g-MAH) blend has higher viscosity at low frequency than the pure PS. Basically as the concentration of PA6 increases, the viscosity at low frequency of the blend decreases. This is acceptable since PA6 has a lower viscosity than PS. The dynamic modulus of the blends has a similar trend to the complex viscosity as shown in Figure 2(b) and Figure 2(c). The loss modulus of the blend at a low frequency is higher than the storage modulus. Table 1 lists the characteristic frequency 
Table 1. Relaxation time of the blends when storage modulus $(G)=$ loss modulus $\left(G^{\prime}\right)$.

\begin{tabular}{ccccccccc}
\hline PS/g-PS/PA6 & $100 / 0 / 0$ & $100 / 6 / 0$ & $90 / 6 / 10$ & $70 / 6 / 30$ & $50 / 6 / 50$ & $30 / 6 / 70$ & $10 / 6 / 90$ & $0 / 0 / 100$ \\
\hline$\omega /{\mathrm{rad} \cdot \mathrm{s}^{-1}}^{125.5}$ & 90.47 & 122.45 & 264.68 & - & - & - & - \\
$1 / \omega, \mathrm{s}$ & 0.0080 & 0.0111 & 0.0082 & 0.0038 & - & - & - & - \\
\hline
\end{tabular}

and relaxation time of the blends when $G=G$ '. The relaxation time is the reciprocal of the characteristic frequency. The 70/6/30 blend has obviously shorter relaxation time for PS-rich blends. In Table 1 when weight content of PA6 is higher than 50 , the loss modulus $\left(G^{\prime}\right)$ is higher than the storage modulus $(G)$ in the experimental frequency range. This means the PA6-rich blends show liquid-like behavior.

\subsection{Interfacial Tension}

The linear viscoelasticity of polymer blends can be described by some emulsion models and the interfacial tension between the blends can be predicted by the models, such as Palierne's model [4]. In general, the models can work well for droplet/matrix morphology and narrow droplet size distribution. Neglecting the surface dilatation modulus and surface shear modulus the simplified Palierne's model [4] [15] is expressed as:

$$
G^{*}(\omega)=G_{m}^{*}(\omega)\left[\frac{1+3 \sum_{i} \varnothing_{i} H_{i}(\omega)}{1-2 \sum_{i} \varnothing_{i} H_{i}(\omega)}\right]
$$

where

$H(\omega)=\frac{4(\alpha / R)\left[2 G_{m}^{*}(\omega)+5 G_{d}^{*}(\omega)\right]+\left[G_{d}^{*}(\omega)-G_{m}^{*}(\omega)\right]\left[16 G_{m}^{*}(\omega)+19 G_{d}^{*}(\omega)\right]}{40(\alpha / R)\left[G_{m}^{*}(\omega)+G_{d}^{*}(\omega)\right]+\left[2 G_{d}^{*}(\omega)+3 G_{m}^{*}(\omega)\right]\left[16 G_{m}^{*}(\omega)+19 G_{d}^{*}(\omega)\right]}(2)$

$\alpha$ is interfacial tension, $\varnothing$ is the volume fraction of the dispersed phase, $R$ is the dispersed particle radius, $G_{d}^{*}$ and $G_{m}^{*}$ is the complex modulus of the dispersed phase and matrix, respectively. In this work, Palierne's model (Equation (1)) is applied to predict the interfacial tension, the results are shown in Figure 3. In general the storage modulus $(G)$ is frequently chosen to be fit since it is more sensitive than the loss modulus $\left(G^{\prime}\right)$ to the interfacial tension. The relation between $G$ and $G^{\prime}$ is $G^{*}=G+G^{\prime}$, which can be found in rheological textbooks. In Equation (1) the variable is $\alpha / R$, the initial value such as $10^{3} \mathrm{~Pa}$ can be assigned to the fitting program, the fitting targets are the experimental values ( $G-\omega, \omega$ is the angular frequency). Run the fitting program, the optimum $\alpha / R$ can be obtained when the fitting curve approaches the experimental data well. The PA6 is considered to be the dispersed phase and PS/PS-g-MAH to be the matrix in Figure 3(a), Figure 3(b) and vice versa in Figure 3(c), Figure 3(d). Figure 3(a) shows the fitting curve for the 90/6/10, Palierne's model with $\alpha / R=$ zero overestimates the storage modulus at low frequency. Figure $3(\mathrm{~b})$ shows good prediction by Palierne's model with $\alpha / R=435.62 \mathrm{~N} / \mathrm{m}^{2}$ for the $70 / 6 / 30$ 

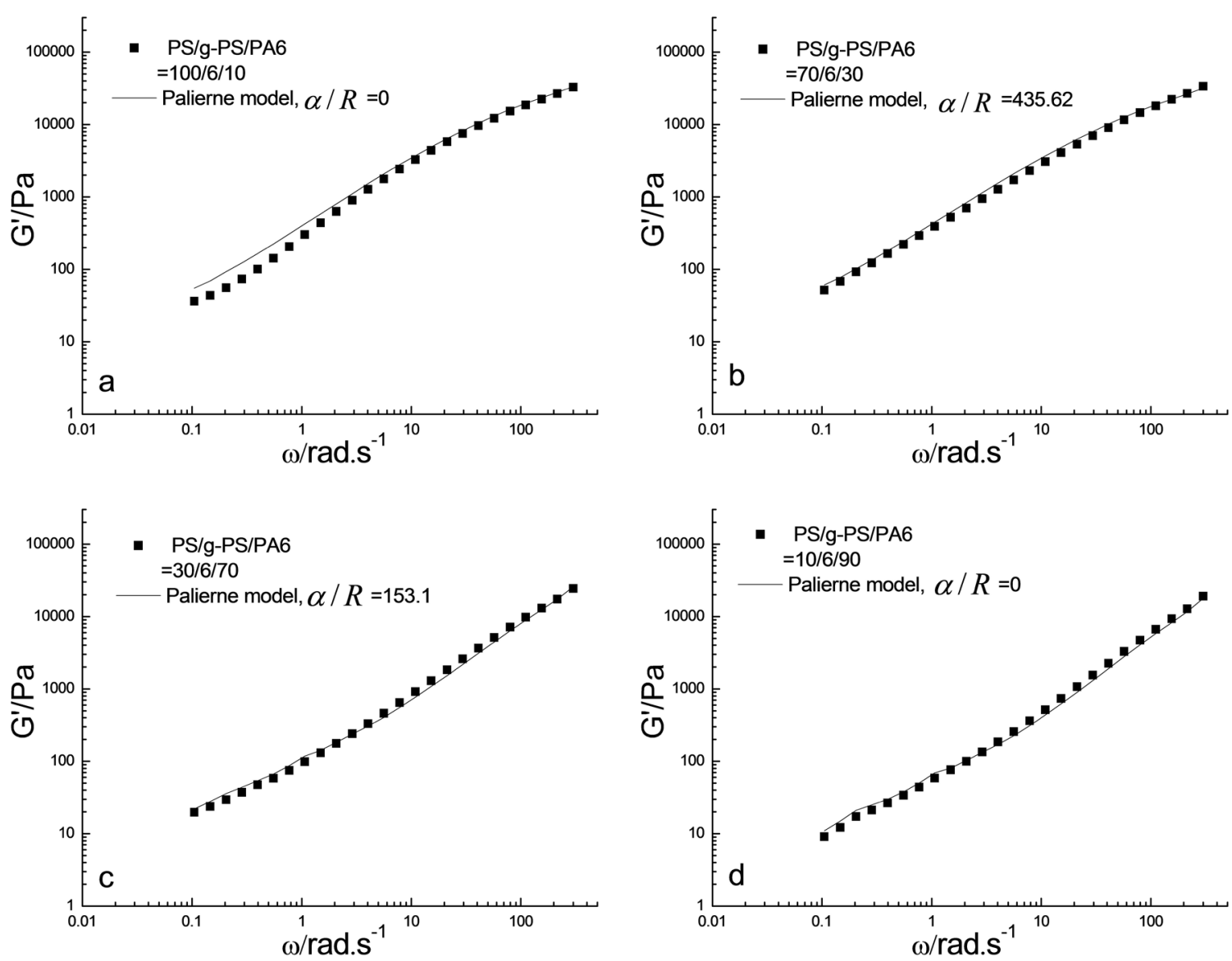

Figure 3. Fit of the dynamic storage modulus data to Palierne model with $\alpha / R$ for the PS/g-PS/PA6 blends.

blend. The average diameter $(2 R)$ is $1.9 \mu \mathrm{m}$, thus the interfacial tension is 0.83 $\mathrm{mN} / \mathrm{m}$. The interface tension of PS/PA6 can be estimated to be $1.5 \mathrm{mN} / \mathrm{m}$ at $230^{\circ} \mathrm{C}$ by referring to the experimental values at $20^{\circ} \mathrm{C}$ (PS: $33 \mathrm{mN} / \mathrm{m}$ and PA6: $42 \mathrm{mN} / \mathrm{m}$ ) [16] and the literature [17]. The reported interfacial tension between immiscible PS/PA6 is $7.4 \mathrm{mN} / \mathrm{m}$ at $230^{\circ} \mathrm{C}$ by Kong et al. [12]. Thus the component of PS-g-MAH has an effect as a compatibilizer between PS and PA6. The polarity of PS was increased by the grafted maleic anhydride, thus the miscibility between PS and PA6 was increased. For the 50/6/50 blend it is not a proper choice to use Palierne's model to predict the data because this model is generally for dispersed phase's volume percentage with no more than $30 \%$. For the 30/6/70 blend, the storage modulus can be fitted well by Palierne's model, the calculated $\alpha / R=153.1 \mathrm{~N} / \mathrm{m}^{2}$, thus the calculated interfacial tension is $0.2 \mathrm{mN} / \mathrm{m}$ with the average droplet diameter being known. For the 10/6/90 blend the storage modulus can be fitted well by Palierne's model with $\alpha / R=0$. This indicates the $10 / 6 / 90$ blend is basically miscible. Lee and Park model [7] was attempted to fit the data and was found to have a similar result, which is not shown here.

\section{Conclusion}

Dynamic rheological behavior of a PS/PS-g-MAH/PA6 blend is investigated in 
this work. In PS-rich blends, the 70/6/30 blend has shorter relaxation time. Due to the viscosity difference, the PA6-rich blends show liquid-like behavior. The storage moduli of the blends are fitted by the Palierne's model, the model overestimates the data for $90 / 6 / 10$, and describes the data well for the $70 / 6 / 30$, 30/6/70 and 10/6/90 blends. The fitting results indicate that PS-g-MAH has an effect as a compatibilizer between PS and PA6. For the 10/6/90 as well as 90/6/10 blend, the fitted results indicate the blends are miscible. For the 70/6/30 and 30/6/70 blends, fitting results show interfacial tension between PS and PA6 decrease, which is due to the effect of PS-g-MAH.

\section{Acknowledgements}

This work is supported by the Top-notch Academic Programs Project of Jiangsu Higher Education Institutions (TAPP) and the Priority Academic Program Development of Jiangsu Higher Education Institutions (PAPD).

\section{Conflicts of Interest}

The authors declare no conflicts of interest regarding the publication of this paper.

\section{References}

[1] Tabatabaei, S.H., Carreau, P.J. and Ajji, A. (2009) Rheological and Thermal Properties of Blends of a Long-Chain Branched Polypropylene and Different Polypropylenes. Chemical Engineering Science, 64, 4719-4731. https://doi.org/10.1016/j.ces.2009.04.009

[2] Hussein, I.A., Hameed, T.H., Abu Sharkh, B.F., et al. (2003) Miscibility of Hexane-LLDPE and LDPE Blends: Influence of Branch Content and Composition Distribution. Polymer, 44, 4665-4672 https://doi.org/10.1016/S0032-3861(03)00437-3

[3] Utracki, L.A. (1989) Polymer Alloys and Blends. Carl Hanser, New York. https://doi.org/10.1021/bk-1989-0395.ch001

[4] Palierne, J.F. (1990) Linear Rheology of Viscoelastic Emulsions with Interfacial Tension. Rheologica Acta, 29, 204-214. https://doi.org/10.1007/BF01331356

[5] Shi, D.A., Ke, Z., Yang, J.H., et al. (2002) Rheology and Morphology of Reactively Compatibilized PP/PA6 Blends. Macromolecules, 35, 8005-8012. https://doi.org/10.1021/ma020595d

[6] Bousmina, M. (1999) Rheology of Polymer Blends: Linear Model for Viscoelastic Emulsions. Rheologica Acta, 38, 73-83. https://doi.org/10.1007/s003970050157

[7] Lee, H.M. and Park, O.O. (1994) Rheology and Dynamics of Immiscible Polymer Blends. Journal of Rheology, 38, 1405-1425. https://doi.org/10.1122/1.550551

[8] Kim, H.J. and Seo, Y. (2003) Effect of Surface Modification on the Interfacial Tension between the Melts of High-Density Polyethylene and Nylon 66: Correlation between Rheology and Morphology. Langmuir, 19, 2696-2704.

https://doi.org/10.1021/la020712y

[9] Gramespacher, H. and Meissner, J. (1992) Interfacial-Tension between Polymer Melts Measured by Shear Oscillations of Their Blends. Journal of Rheology, 36, 1127-1141. https://doi.org/10.1122/1.550304 
[10] Yu, W., Zhou, W. and Zhou, C. (2010) Linear Viscoelasticity of Polymer Blends with Co-Continuous Morphology. Polymer, 51, 2091-2098.

https://doi.org/10.1016/j.polymer.2010.03.005

[11] Ishigami, A., Nishitsuji, S., Kurose, T. and Ito, H. (2019) Evaluation of Toughness and Failure Mode of PA6/mSEBS/PS Ternary Blends with an Oil-Extended Viscoelastic Controlled Interface. Polymer, 177, 57-64. https://doi.org/10.1016/j.polymer.2019.05.066

[12] Kong, M., Huang, Y., Chen, G., Yang, Q. and Li, G.X. (2011) Retarded Relaxation and Breakup of Deformed PA6 Droplets Filled with Nanosilica in PS Matrix during Annealing. Polymer, 52, 5231-5236. https://doi.org/10.1016/j.polymer.2011.08.052

[13] Wang, J., Tang, Q., Ren, X., et al. (2019) Selectively Localized Nanosilica Particles at the Phase Interface of PS/PA6/Nanosilica Composites with Co-Continuous Structure via Reactive Extrusion. Composites Science and Technology, 172, 125-133. https://doi.org/10.1016/j.compscitech.2019.01.016

[14] Tol, R.T., Mathot, V.B.F. and Groeninckx, G. (2005) Confined Crystallization Phenomena in Immiscible Polymer Blends with Dispersed Micro- and Nanometer Sized PA6 Droplets, Part 2: Reactively Compatibilized PS/PA6 and (PPE/PS)/PA6 blends. Polymer, 46, 383-396. https://doi.org/10.1016/j.polymer.2004.10.070

[15] Asthana, H. and Jayaraman, K. (1999) Rheology of Reactively Compatibilized Polymer Blends with Varying Extent of Interfacial Reaction. Macromolecules, 32, 3412-3419. https://doi.org/10.1021/ma980181d

[16] Wu, R.J. (1998) Polymer Interface and Adhesion. Science Press, Beijing.

[17] Zhang, Z.Y. and Qiao, J.L. (1993) Method of Estimating Interfacial Tension in Polymer Systems. Acta Polymerica Sinca, 3, 343-347. 